\title{
Experimentally produced prior residence effect in male convict cichlids: The role of initial proximity to territorial markers
}

\author{
MICHAEL H. FIGLER and JOAN EVENSEN \\ Towson State University, Baltimore, Maryland 21204
}

\begin{abstract}
Investigating the effects of initial proximity to territorial markers on experimentally produced prior residence effects, 16 pairs of male convict cichlids were randomly assigned to two treatment conditions: a nonreversal condition where the natural resident was closest to the territorial markers at the onset of the encounter, or a reversal condition where the intruder had initially closer proximity to these cues. Results showed that the proximity variable did not change the relative frequency of dominance by the natural resident. The relative frequency of natural residents biting first was also not affected by the proximity variable. As in past studies, the natural residents significantly dominated over intruders, and bit first more frequently, with biting first being a reliable predictor of eventual dominance.
\end{abstract}

In a recent series of experiments using the jewel fish, Hemichromis bimaculatus (Gill) (de Boer \& Heuts, 1973; Figler, Klein, \& Peeke, 1976), and the convict cichlid, Cichlasoma nigrofasciatum (Günther) (Figler \& Peeke, 1978), it has been demonstrated that giving an animal a few days alone in an aquarium with appropriate territorial markers subsequently confers a dominance advantage over a conspecific intruder. The phenomenon of a territorial resident dominating an intruder is a well know one, occurring in a number of diverse phyla, and has been termed "the prior residence effect" (Braddock, 1949; Denny \& Ratner, 1970). A related phenomenon, "the prior exposure effect," refers to the situation where two territorial conspecifics meet in an area other than their home territories, but this "new" area resembles one territory more than the other. The animal whose home territory most resembles this extraterritorial area has a significant dominance advantage over his rival. The dominance advantage in this situation (extraterritorial encounter) has been termed the prior exposure effect (de Boer \& Heuts, 1973; Figler, Dyer, Streckfus, \& Nardini, 1975).

In all the above-cited studies, it is most important to note that dominant animals have been produced simply by giving them prior residence in an aquarium with only minimal visual contact with a neighboring conspecific. That is, dominance eventuates without the residential animal having had a prior direct encounter with another conspecific. Also, experimental dominance encounters never involve two fish that have had such prior visual contact. Therefore, the problem exists as to what produces the experimentally created prior residence or

Requests for reprints should be sent to Michael H. Figler, Department of Psychology, Towson State University, Baltimore, Maryland 21204. exposure effects. In a series of experiments that manipulated levels of aggression in male convict cichlids by means of ethanol, Figler and Peeke (1978) showed that increasing or decreasing intruder aggression did not appreciably change the prior residence effect. However, when residents were given an aggression-decreasing dose, the effect was obliterated. An aggression-increasing dose of ethanol given to residents did not change their dominance advantage, most likely due to a ceiling effect. In that experiment, in a no-alcohol condition, residents dominated intruders in $94 \%$ of the encounters. The results indicated that the prior residence effect is due to some behavioral/morphological changes in the resident that accompany the establishment of a territory, with the subsequent dominance advantage being a direct or indirect (intruder reactions to these resident changes) result of such alterations.

The most obvious consequence of establishing a territory is that the resident is in close proximity to the territorial markers (e.g., stones, vegetation). Figler et al. (1976) have suggested that the prior residence effect as seen in the natural habitat could possibly be due to the association of a territorial resident with a preferred territorial marker, this proximity being sufficient in conferring a liability on an intruder, from the intruder's vantage point. Such also could be the case in all previous laboratory studies, since the initial dominance encounter has ensued after both combatants have been removed from their respective aquaria, a partition bisecting the resident's aquarium has been inserted, with the resident being put back into that half containing the territorial markers, and the intruder on the other side.

If this variable of initial proximity to territorial markers is an important one in producing the prior residence effect, then reversing the combatants in the test aquarium prior to the initial encounter should 
diminish the dominance advantage of the resident (i.e., the previous occupant of the aquarium). In that paradigm, combatants would initially meet with the intruder (previous occupant of another aquarium) being closer to the territorial markers. The following experiment was undertaken to evaluate this proximity hypothesis.

\section{METHOD}

\section{Subjects}

A total of 32 adult male convict cichlids, $C$. nigrofasciatum, obtained from a commercial supplier, were used in the present study. They were held in several large community holding tanks before being transferred to individual aquaria $(41 \times 21 \times 26 \mathrm{~cm}$, 21 liters). They were fed daily with frozen brine shrimp (Artemia salina). Water temperature was maintained at $23^{\circ} \mathrm{C} \pm 2^{\circ} \mathrm{C}$ by individual tank heaters for the holding tanks, and by a thermostatically controlled laboratory heating system for the experimental aquaria. Overhead lighting was on a 12-h on/12-h off automatic system.

\section{Apparatus}

The individual aquaria were of identical dimensions and contained a coarse gravel substrate and either one $7.5-\mathrm{cm}$-diam terra cotta pot placed on its side or a clump of four green plastic plants (resembling Fontinalis antipyretica) approximately $9 \mathrm{~cm}$ high. These plants were grouped together and placed $2 \mathrm{~cm}$ from the glass along one short side of the aquaria.

The aquaria were arranged, with the short sides touching, in rows, so that one long side of each looked out on the laboartory. Cardboard partitions were used to prevent the fish from seeing any but one other fish, that one always being from the other treatment condition, and not the fish to be met in the experimental testing situation. The stimuli in the adjoining aquaria were placed in the far side of each. This procedure is similar to that used previously by Figler and Peeke (1978) to help reduce fright behavior in testing situations.

\section{Procedure}

Individual fish were maintained in separate home aquaria for 5 days to allow for acclimation to the experimental setting and establishment of territories. These fish were then assigned to pairs, with the only stipulations being that each pair member be from a different treatment condition and that the pair members not differ by more than $5 \%$ in body length. Again, during the acclimation period, none of the fish was exposed to the one with whom the dominance encounter would occur.

After the 5-day period, dominance encounters took place in the aquaria in which fish had established territories. The aquarium to be used was bisected into two compartments $(20.5 \times 21 \mathrm{~cm})$ by an opaque Plexiglas shield. Half of the encounters took place in aquaria containing the pot and half in the planted aquaria. In one treatment condition, the resident was removed and replaced (to control for handling effects) on the side of the tank containing the familiar territorial markers (nonreversal condition). In the other treatment group (reversal condition), the resident fish was removed, the partition inserted, and the intruder was placed in the compartment containing the unfamiliar (to him) territorial markers. The natural resident was replaced into the other compartment. A 15-min adaptation period was then allowed, after which the partition was removed and the dominance encounter began.

During the ensuing dominance encounter, several events were recorded: the length of time to the first bite, which fish bit first, the victor, and the duration of the bout. A fish was declared victorious when it showed six consecutive dominance behaviors, such as biting or butting the other fish associated with or immediately followed by escape movements or submissive display by the one attacked, or frontal or lateral displays followed by escape movements or submissive behavior (see de Boer \& Heuts, 1973; Figler \& Peeke, 1978, for a more complete description). Those trials that yielded no fighting behavior within $30 \mathrm{~min}$ were terminated and not used in the data analyses.

\section{RESULTS}

The data were tabulated on 15 pairs of fish, since 1 pair showed no aggressive behavior. Statistical tests were performed using two-tailed Fisher exact probability tests (Siegel, 1956), unless otherwise specified.

Of the 15 paired encounters, the natural residents dominated in 12 , a highly significant finding $(\mathrm{p}<.01)$. When comparing the treatment conditions, it was found in the nonreversal condition that six out of seven natural residents dominated, while in the reversal condition, six out of eight natural residents dominated. These treatment differences in the relative frequencies of dominance were not significant $(p>.05)$. Therefore, the reversal-nonreversal variable did not produce a change in the relative dominance frequency by the natural resident.

It was also found that across treatments, 11 out of 15 natural residents bit first in the encounter, a highly significant finding $(p<.01)$. In the nonreversal condition, six out of seven natural residents bit first, while natural residents bit first in five of eight encounters in the reversal condition. The Fisher exact test showed no significant differences between treatment conditions in the relative number of bouts in which the natural resident bit first $(p>.05)$. The variable of biting first was found to be highly predictive of eventual dominance. The fish that bit first eventually dominated his partner in 12 of the 15 encounters, a highly significant effect $(p<.01)$. Finally, the two treatment conditions were compared on each of two measures: elapsed time from the beginning of the bout until the first bite, and total bout duration. Using Mann-Whitney U tests (Siegel, 1956), no treatment differences were uncovered for either of these measures $(p>.05)$.

\section{DISCUSSION}

An initial encounter between a territorial resident and an intruder, when the intruder has closer initial proximity to the territorial markers (central part of the territory), does not appreciably change the dominance advantage of the resident. The experimental paradigm used in the present study probably bears most resemblance to a resident leaving his territory temporarily and finding it occupied upon returning. In a field study of Haplochromis burtoni, Fernald and Hirata (1977) provide qualitative data showing that the returning resident inevitably displaces the territorial intruder. The present data show similar effects in a laboratory facsimile of that situation. The reversal condition did not significantly change the dominance advantage of the natural resident. It should be noted that the resident in the reversal condition continues to have many familiar visual-spatial and olfactory cues at his disposal, 
possibly facilitating maintenance of dominance, even though the intruder is at the center of the territory. The intruder in the reversal condition did not simply yield to the natural resident, but initially stayed close to the vegetation or in the pot, and then actively defended it. The natural resident in both conditions also did not hesitate in attempting to drive off the intruder. In only one pair in the entire experiment did a fight fail to occur (nonreversal condition); in only one pair did the natural resident drive off the intruder with no resistance (nonreversal condition); and in only one pair did the intruder successfully defend his newly acquired territory with no counterattack from the natural resident (reversal condition). In the other pairs, the fighting was similar to that described by Figler and Peeke (1978). Also, as in previous studies of jewel fish (de Boer \& Heuts, 1973; Figler et al., 1975; Figler et al., 1976) and convict cichlids (Figler \& Peeke, 1978), the present data showed that the natural resident typically bites first, and that this variable is a reliable predictor of eventual dominance. In conclusion, the experimentally produced prior residence effect is not due simply to the initially closer proximity of the resident to the territorial markers. The previous studies' results must be due to factors other than this initial proximity variable.

\section{REFERENCES}

BRADDOCK, J. C. The effect of prior residence upon dominance in the fish Platypoecilus maculatus. Physiological Zoology, 1949, 22, 161-169. de Boer, J. N., \& Heuts, B. A. Prior exposure to visual cues affecting dominance in the jewel fish, Hemichromis bimaculatus Gill 1862 (Pisces, Cichlidae). Behaviour, 1973, 44, 299-321.

DenNy, M. R., \& RATNER, S. C. Comparative psychology: Research in animal behavior (rev. ed.). Homewood, Ill: Dorsey Press, 1970.

Fernald, R. D., \& Hirata, N. R. Field study of Haplochromis burtoni: Quantitative behavioral observations. Animal Behaviour, 1977, 25, 964-975.

Figler, M. H., Dyer, R. S., Streckfus, C. F., \& Nardini, $K$. M. The establishment of dominance relationships in the jewel fish, Hemichromis bimaculatus (Gill), as related to prior exposure to and configuration of visual cues. Behavioral Biology, $1975,14,241-245$.

Figler, M. H., Klein, R. M., \& Peeke, H. V. S. The establishment and reversibility of dominance relationships in jewel fish, Hemichromis bimaculatus Gill (Pisces, Cichlidae): Effects of prior exposure and prior residence situations. Behaviour, 1976, 58, 254-271.

Figler, M. H., \& Peeke, H. V. S. Alcohol and the prior residence effect in male convict cichlids (Cichlasoma nigrofasciatum). Aggressive Behavior, 1978, 4, 125-132.

SIEGEL, S. Nonparametric statistics for the behavioral sciences. New York: McGraw-Hill, 1956.

(Received for publication January 3, 1979.) 